\title{
Durable Reaction Material Development for Magnesium Oxide/Water Chemical Heat Pump
}

\author{
Yukitaka KATO, Tomofumi SAITO, Tsutomu SogA, \\ Junichi RYU and Yoshio YoshIZAWA \\ Research Laboratory for Nuclear Reactors, \\ Tokyo Institute of Technology, \\ 2-12-1-N1-22, Ookayama, Meguro-ku, Tokyo 152-8550, Japan
}

Keywords: Chemical Heat Pump, Repetitive Operation, Reaction Material Durability, Magnesium Oxide, Magnesium Hydroxide

\begin{abstract}
Durable reaction material for repetitive reaction operation of a chemical heat pump that used a reversible magnesium oxide/water reaction system was discussed to enhance the heat pump performance. Because a material for the heat pump use was required to fit multi-production process, a molding method was introduced for material preparation. Some molded samples under different preparation conditions were evaluated kinetically by a thermo-balance analysis. Magnesium hydroxide prepared from ultra fine particle magnesium oxide and purified water showed enough reactivity, and also stable durability to 70 of repetitive reaction cycles. Removal of impurity was effective for durability enhancement of magnesium hydroxide made from seawater precipitated precursor. The cost of the precipitated hydroxide was less than one several tenths of the ultra fine particle material. It was demonstrated that the molded reactant made from precipitated hydroxide was applicable for multi production and cost reduction of magnesium hydroxide material for the heat pump. The thermal performance of magnesium oxide/water chemical heat pump was evaluated from experimental results.
\end{abstract}

\section{Introduction}

Chemical heat pumps have possibility to develop a new thermal energy conversion market. The thermal performance of a chemical heat pump depends on the reaction system used in it. Solid-gas reaction system is expected as candidate for thermal utilization because of high-energy storage density, reaction reversibility with no side reaction, and small work for reactant separation.

Magnesium oxide has possibility for thermal utilization also as an inorganic oxide (Ervin, 1977). A chemical heat pump using a reversible magnesium oxide/water reaction system has been examined to promote thermal energy utilization (Bauerle and Chung, 1980; Bhatti and Dollimore, 1984). The heat pump examined in this study is based on the following chemical reactions:

$$
\begin{gathered}
\mathrm{MgO}(\mathrm{s})+\mathrm{H}_{2} \mathrm{O}(\mathrm{g})=\mathrm{Mg}(\mathrm{OH})_{2}(\mathrm{~s}), \\
\Delta H^{\circ}{ }_{1}=-81.02 \mathrm{~kJ} / \mathrm{mol} \\
\mathrm{H}_{2} \mathrm{O}(\mathrm{g})=\mathrm{H}_{2} \mathrm{O}(\mathrm{l}), \quad \Delta{H^{\circ}}_{2}=-40.02 \mathrm{~kJ} / \mathrm{mol}
\end{gathered}
$$

Received on July 13, 2007; accepted on August 23, 2007. Correspondence concerning this article should be addressed to Y. Kato (E-mail address: yukitaka@nr.titech.ac.jp).

Presented at International Symposium on Innovative Materials for Processes in Energy Systems, IMPRES, Kyoto, October, 2007.
This heat pump makes it possible to store and transform thermal energy on demand using both the hydration of magnesium oxide $(\mathrm{MgO})$ and the dehydration of magnesium hydroxide $\left(\mathrm{Mg}(\mathrm{OH})_{2}\right)$. A previous study showed that the heat pump could be used as a heat amplifier to transform a heat source at $70-90^{\circ} \mathrm{C}$ to one at $100-150^{\circ} \mathrm{C}$ by storing heat at a temperature of $350^{\circ} \mathrm{C}$ (Kato et al., 1993). The pump is expected to contribute to load leveling in electrical power generation systems by storing surplus electricity generated during the night as heat energy and re-supplying it to users during peak-demand periods. The heat pump is also effective for co-generation system by utilizing surplus heat in the exhaust gas generated from a cogeneration engine.

Previous studies demonstrated that the hydration of $\mathrm{MgO}$ controlled the overall rate of heat pump operation. A rate equation was proposed for hydration based on an experimental kinetic study using a thermobalance (Kato et al., 1996), and the feasibility of the heat pump was discussed. Heat pump operation was demonstrated using a laboratory-scale heat pump with a packed reactor bed (Kato et al., 2001, 2003). The pump had a heat output of up to $100 \mathrm{~W} / \mathrm{kg}$. The results showed that the heat pump had practical possibility.

Both hydration of $\mathrm{MgO}$ and dehydration of $\mathrm{Mg}(\mathrm{OH})_{2}$ are achieved during one cycle of operation. For practical utilization of the heat pump, more than 100 repetitions of the cycle are required. Therefore, 
Table 1 Physical properties of V05Gs

\begin{tabular}{lcccc}
\hline Sample & Pre-cursor & $\begin{array}{c}\text { Moisture of precursor } \\
\text { paste }[\%]\end{array}$ & $\begin{array}{c}\text { BET specific surface } \\
\text { area }\left[\mathrm{m}^{2} \cdot \mathrm{g}^{-1}\right]\end{array}$ & $\begin{array}{c}\text { Apparent particle } \\
\text { diameter }[\mu \mathrm{m}]\end{array}$ \\
\hline V05G-40 & & 40 & 29.4 & 5.8 \\
V05G-45 & UFP MgO & 45 & 27.1 & 5.8 \\
V05G-50 & & 50 & 32.4 & 5.8 \\
\hline
\end{tabular}

the reaction material chosen for the heat pump must be capable of enduring repetitive reaction. The reaction cycles for both hydration and dehydration of some $\mathrm{MgO}$ materials has been examined. $\mathrm{MgO}$ material using ultra fine powder (UFP) of magnesium oxide as the precursor showed durability to repetitive reaction of 24 cycles was expected as one of appropriate materials for the heat pump (Kato et al., 1998). Reactant for the heat pump is preferred to be produced from mass production process for conventional use. However, the ultra fine material had been prepared by handmade and complicated processes, that is, produce of dried solid mass $\mathrm{Mg}(\mathrm{OH})_{2}$, crash of the mass into particles, and passing materials into sieve for obtaining of desired diameter fraction particles with low-yield. It was required to develop production process matching with mass-production for market development of the heat pump with high-yield and stable production. Then, a molding method using an extruder was introduced in the material preparation because the method was expected to be suitable for mass production and realize homogeneous quality of product. Molded materials were prepared in some production conditions and examined durability under repetitive cycles longer than previous experiment in a thermo-balance in this study.

Cost reduction of material is also one of important terms for the heat pump material. UFP of magnesium oxide needs special vacuum chamber for production and fairly large energy consumptions for raw metal magnesium and UFP production processes, and the cost is generally $10,000 \mathrm{JPY} / \mathrm{kg}$ (=80-90 USD $/ \mathrm{kg}$ ). Change from expensive material of the UFP $\mathrm{MgO}$ into lower cost one of conventional $\mathrm{MgO}$ was preferable because market price of the latter is less one several tenths of the former. It had been concluded that impurity reduction from row material was effective for durability enhancement of MgO (Kato et al., 1999). Then, a material made by removal of impurity from conventional $\mathrm{MgO}$ was examined for durability enhancement to repetitive cycle operation. Contribution of the developed materials to the chemical heat pump was evaluated from measured experimental results.

\section{Experimental}

\subsection{Materials}

UFP and seawater precipitated $\mathrm{MgO}$ materials were used as precursors of experimental reactant of

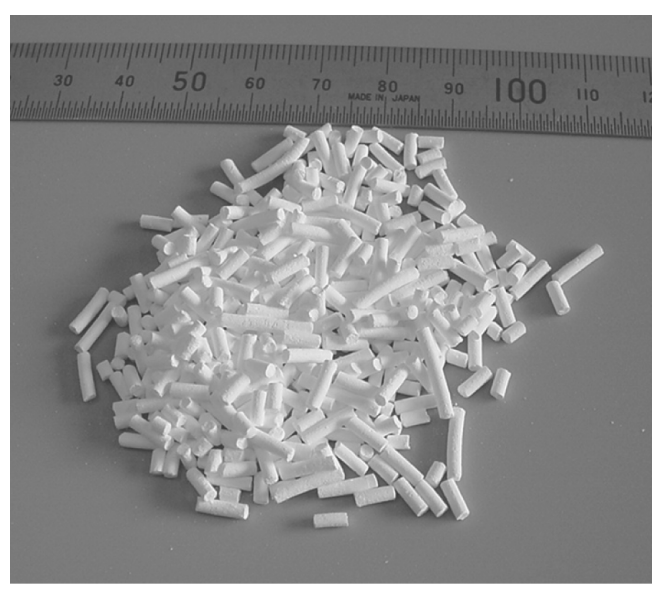

Fig. 1 V05G-40 of molded reactant of $\mathrm{Mg}(\mathrm{OH})_{2}$ (diameter of $1.9 \mathrm{~mm}$ and length of $5-10 \mathrm{~mm}$ )

$\mathrm{Mg}(\mathrm{OH})_{2}$, respectively. The sample materials of the $\mathrm{Mg}(\mathrm{OH})_{2}$ were prepared by the cooperation with UBE Material Industries, Ltd.

$\underline{\text { 1.1.1 UFP } \mathrm{Mg}(\mathrm{OH})_{2}} \quad$ UFP $\mathrm{MgO}$ (primary particle diameter of $50 \mathrm{~nm}$, UBE Material Industries, Ltd.) was used as high purity material of precursor. The precursor was hydrated with purified water. After hydration, the pasty products of $\mathrm{Mg}(\mathrm{OH})_{2}$ were dried to a level of some moisture and were molded in a cylindrical shape by an extruder. The moldings were dried completely later. The cylindrical molded materials of $\mathrm{Mg}(\mathrm{OH})_{2}$ had a diameter of $1.9 \mathrm{~mm}$ and lengths of 5-10 $\mathrm{mm}$. Degree of moisture of the pasty products was effective for the reactivity of the molded material and load of the extruder. Pasty products having water concentration of 40, 45 and $50 \mathrm{wt} \%$ were used for the molding reactant preparation. The moldings were named as V05G-40, V05G-45 and V05G-50, respectively. Physical properties of them are shown in Table 1. Figure 1 shows appearance of sample of the V05G-40. Apparent particle diameter was measured by laser diffraction.

1.1.2 Seawater precipitated $\mathrm{Mg}(\mathrm{OH})_{2} \quad$ A conventional $\mathrm{Mg}(\mathrm{OH})_{2}\left(\mathrm{~L}_{3} \mathrm{G}_{\text {raw }}\right.$, UBE Material Industries, Ltd.) extracted from seawater by precipitation method was used for another precursor. Because the material is made from plentiful seawater, the price of around $100 \mathrm{JPY} / \mathrm{kg}$ (=less $1 \mathrm{USD} / \mathrm{kg}$ ) is clearly more costeffective than UFP one. The chemical heat pump would convert waste heat into value added thermal energy. 
Table 2 Impurity concentrations of $\mathrm{Mg}(\mathrm{OH})_{2}$ materials

\begin{tabular}{|c|c|c|c|c|c|c|c|c|c|c|}
\hline \multirow[t]{2}{*}{ Sample } & \multirow{2}{*}{$\begin{array}{c}\text { Purity of } \\
\mathrm{MgO} \\
{[\%]}\end{array}$} & \multicolumn{7}{|c|}{ Concentration [ppm] } & \multirow{2}{*}{$\begin{array}{c}\text { BET specific } \\
\text { surface area } \\
{\left[\mathrm{m}^{2} \cdot \mathrm{g}^{-1}\right]}\end{array}$} & \multirow{2}{*}{$\begin{array}{c}\text { Apparent particle } \\
\text { diameter } \\
{[\mu \mathrm{m}]}\end{array}$} \\
\hline & & $\mathrm{Ca}$ & $\mathrm{Si}$ & $\mathrm{Fe}$ & $\mathrm{Al}$ & B & $\mathrm{Cl}$ & S & & \\
\hline $\mathrm{L} 3 \mathrm{G}_{\mathrm{raw}}$ & 97.5 & 1100 & 610 & 200 & 200 & 42 & 600 & 2800 & 13 & 1.8 \\
\hline L3G $\mathrm{G}_{\text {treat }}$ & & 640 & 330 & 140 & 140 & 43 & 70 & 633 & 5 & 1.9 \\
\hline V05G-40 & $>99.98$ & 2 & 7 & 13 & $<1$ & $<1$ & 15 & 4 & 29.4 & 5.8 \\
\hline
\end{tabular}

The heat pump itself is required to be low-cost. The cost reduction of charged reaction materials for the heat pump is a keen point for practical market development of the heat pump. Then, durability improvement of conventional material of $\mathrm{L} \mathrm{G}_{\text {raw }}$ was examined in this study as following. Impurity in $\mathrm{L}^{3} \mathrm{G}_{\text {raw }}$ was removed by calcination treatment.

Resulted $\mathrm{MgO}$ material was hydrated into $\mathrm{Mg}(\mathrm{OH})_{2}$ and molded into a cylindrical form in the same size and manners of $\mathrm{V} 05 \mathrm{Gs}$, and named as L3 $\mathrm{G}_{\text {treat }}$. Molded L3G $\mathrm{G}_{\text {raw }}$ in the same cylindrical form was also prepared as reference material to compare with $\mathrm{L} \mathrm{G}_{\text {treat }}$. Impurity concentrations of $\mathrm{L} \mathrm{G}_{\text {raw }}, \mathrm{L} 3 \mathrm{G}_{\text {treat }}$ and V05G-40 are shown in Table 2.

\subsection{Kinetic measurement experiment}

The material reaction durability was measures by a thermo-balance (TGD-9600, ULVAC-RIKO, Inc.) under a flow system. A material sample, which was just molded raw material, of about $15 \mathrm{mg}$ placed in a platinum cell was installed in the reactor of the balance. The temperature at the bottom of the cell, which was considered to be the reaction temperature, was measured by a thermocouple and controlled by an electric furnace. Each repetitive experiment was proceeded as following sequence.

During dehydration of $\mathrm{Mg}(\mathrm{OH})_{2}$, argon gas of $100 \mathrm{~mL}-\mathrm{STP} \cdot \mathrm{min}^{-1}$ was flown in the balance to remove generated vapor at a temperature of $350^{\circ} \mathrm{C}\left(T_{\mathrm{d}}\right)$. During hydration of $\mathrm{MgO}$, argon gas of $45 \mathrm{~mL}-\mathrm{STP} \cdot \mathrm{min}^{-1}$ as a carrier gas was passed into a water evaporator in which constant amount of $33.4 \mu \mathrm{L} \cdot \mathrm{min}^{-1}$ of purified water was supplied from a micro-feeder. The water vapor and gas mixture under a partial vapor pressure $\left(P_{\mathrm{h}}\right)$ of $48 \mathrm{kPa}$, which corresponds to a saturated vapor pressure at a temperature $\left(T_{\mathrm{s}}\right)$ of $80^{\circ} \mathrm{C}$, was supplied in the balance for the hydration at a temperature $\left(T_{\mathrm{h}}\right)$.

The reactor's mass change due to the reaction, $\Delta m$ [g], was caused by the movement of vapor. Thus, the mole reacted fraction, $x[-]$, is defined as follows.

$$
x=1+\frac{\left(\Delta m / M_{\mathrm{H}_{2} \mathrm{O}}\right)}{\left(m_{\mathrm{Mg}(\mathrm{OH})_{2}} / M_{\mathrm{Mg}(\mathrm{OH})_{2}}\right)}
$$

where $m_{\mathrm{Mg}(\mathrm{OH})_{2}}[\mathrm{~g}], M_{\mathrm{Mg}(\mathrm{OH})_{2}}\left[\mathrm{~g} \cdot \mathrm{mol}^{-1}\right]$ are initial charged mass of $\mathrm{Mg}(\mathrm{OH})_{2}$ in the cell and the molecu-
Table 3 Hydration performances of V05Gs in the first cycle

\begin{tabular}{lccc}
\hline Sample & $\Delta x_{120}[\mathrm{~mol} \%]$ & $\rho\left[\mathrm{g} \cdot \mathrm{cm}^{-3}\right]$ & $\rho \Delta x_{120}$ \\
\hline V05G-40 & 65.7 & 0.485 & 0.319 \\
V05G-45 & 64.2 & 0.458 & 0.294 \\
V05G-50 & 66.1 & 0.434 & 0.287 \\
\hline
\end{tabular}

lar mass of $\mathrm{Mg}(\mathrm{OH})_{2}$. The hydration experiments started from the dehydrated state. The dehydration of each sample did not proceed to $x=0$ due to the existence of structural water in the reactant, and the sample saturated at around $x=0.1$. Hydration saturated at around $x=0.7$. In order to obtain an objective comparison of the reaction reactivity, the mole reacted fraction change, $\Delta x[\mathrm{~mol} \%]$, is defined as follows.

$$
\Delta x=x-x_{\text {ini }}
$$

where $x_{\text {ini }}$ is the initial reacted fraction of hydration in a reaction cycle.

\section{Results and Discussion}

\subsection{Ultra fine particle materials}

The first hydration reactivities of V05Gs were compared by a thermo-balance measurement under condition of $T_{\mathrm{h}}=110^{\circ} \mathrm{C}, P_{\mathrm{h}}=48 \mathrm{kPa}$ and $T_{\mathrm{s}}=80^{\circ} \mathrm{C}$. Attained reacted fraction changes in hydration after $120 \mathrm{~min}, \Delta x_{120}$, and reaction densities, $\rho \Delta x_{120}\left[\mathrm{~g} \cdot \mathrm{cm}^{-3}\right]$, are shown in Table 3. The result indicated that lower moisture would be applicable for higher reaction density. However, the extruder had lower limitation for moisture, because higher viscosity at lower moisture paste made difficulty for stable extrusion operation. Then, the V05G-40 was chosen as the most applicable reactant in the materials because it had the highest reaction density and the moisture value was the lowest limitation for stable extrusion process in the process.

The durability to the repetitive cycle of V05G-40 was examined for 70 cycles under $T_{\mathrm{h}}=110^{\circ} \mathrm{C}, P_{\mathrm{h}}=$ $48 \mathrm{kPa}$ and cyclic hydration time $\left(t_{\mathrm{h}}\right)$ of $60 \mathrm{~min}$. It was presumed that the chemical heat pump was operated once a day storing co-generation exhaust gas in winter season and for two months, then, the cycle times was 


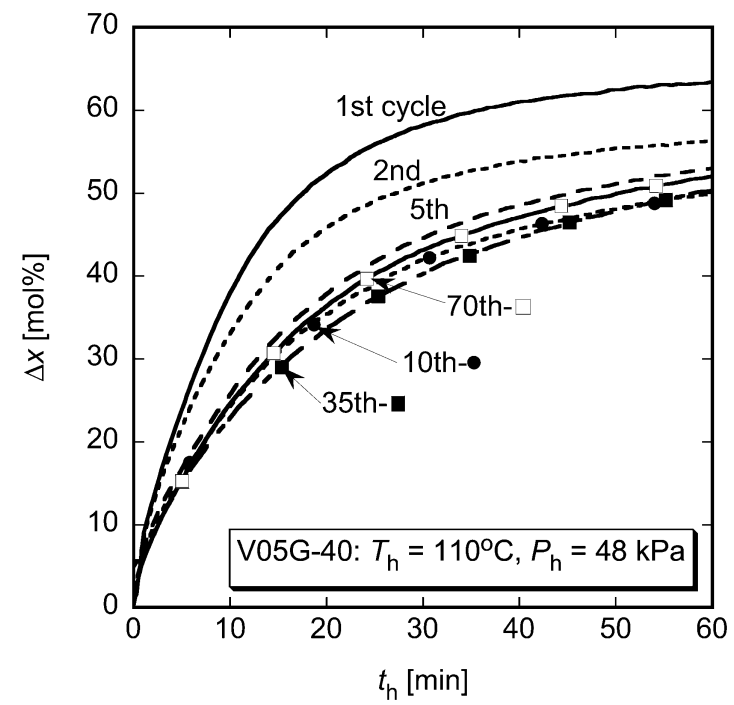

Fig. 2 Hydration reactivity change during repetitive cycle of 70 times for V05G-40

targeted. The result of the hydration of the material in the cyclic operation is shown in Figure 2. The reactivity decreased during initial less than 5 cycles, but remained constant from 10th to 70th cycle. SEM photographs of the hydrated materials are shown in Figure 3. Agglomeration between primary particles was developed gradually from original material in Figure 3(a) to 70th cycle in Figure 3(c). However, from the result of Figure 2, it was supposed that reaction in primary particle limited overall reaction and the agglomeration did not effect on the hydration reaction rate during repetitive cycle. The bulk shape of the molded particle was kept well after the cyclic operation. V05G-40 was expected to have some extent of repetitive operation durability. On the other hand, a methodology for protection to the agglomeration still is needed for longer repetitive operation.

\subsection{Precipitated materials}

The hydration reactivity of materials of $\mathrm{L}_{3} \mathrm{G}_{\text {raw }}$, L3 $\mathrm{G}_{\text {treat }}$ and V05G-40 in repetitive cycle were compared under $T_{\mathrm{h}}=120^{\circ} \mathrm{C}, P_{\mathrm{h}}=48 \mathrm{kPa}$ as shown in Figure 4. L3 $\mathrm{G}_{\text {treat }}$ had higher reactivity compared with $\mathrm{L} 3 \mathrm{G}_{\text {raw }}$ in all over cycles, and similar durability with V05G-40 in the initial 11 cycles. $\mathrm{L}_{3} \mathrm{G}_{\text {treat }}$ was eliminated well chloride and sulfur ions from precursor of $\mathrm{L}_{3} \mathrm{G}_{\text {raw }}$. Chloride ion tends to form magnesium chloride, $\mathrm{MgCl}_{2}$, with magnesium ion.

$\mathrm{Mg}(\mathrm{OH})_{2}$ and $\mathrm{MgO}$ have a hexagonal and square crystal structure, respectively (Itatani, 1988). The reactive nuclei production by the structure change from $\mathrm{Mg}(\mathrm{OH})_{2}$ to $\mathrm{MgO}$ has positive effect to hydration reactivity enhancement (Kato et al., 1999). Stable material formations from magnesium ion and chloride or sulfur ions had possibility to inhibit the nuclei production, to enhance the agglomeration and to reduce re-
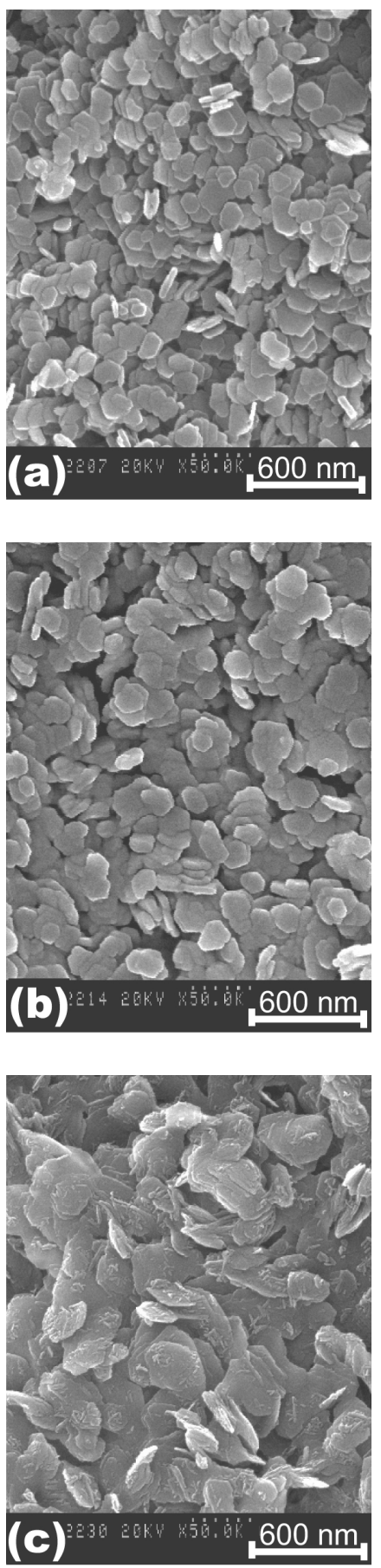

Fig. 3 SEM photographs of hydrated materials of V05G40 after cyclic pperations: (a) original material; (b) after 2nd cycle; (c) after 70th cycle

petitive durability. V05G-40 was superior to $\mathrm{L} 3 \mathrm{G}_{\text {treat }}$ after larger cycle times. It showed that agglomeration of particles in V05G-40 was more moderate than L3 $\mathrm{G}_{\text {treat }}$. However, the figure shows that impurity elimination is effective for durability enhancement. Cost of the precipitated material precursor is less than one several tenths of one of UFP. Although the $\mathrm{L}_{3} \mathrm{G}_{\text {treat }}$ tended to be inferior to V05G-40 in repetitive durability, the 


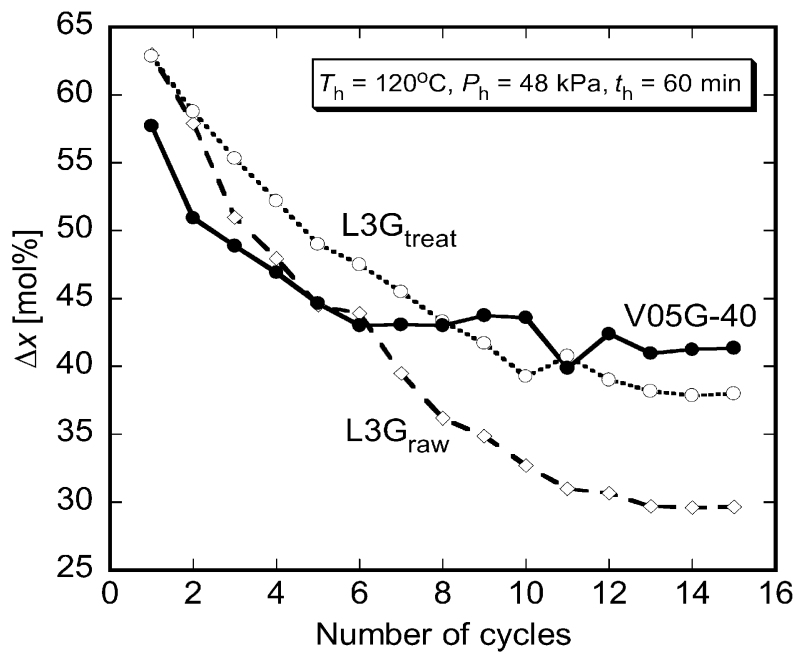

Fig. 4 Hydration reactivity in repetitive cycle of $\mathrm{Mg}(\mathrm{OH})_{2}$ made from precursors of precipitated and UFP $\mathrm{MgO}$

former had obviously cost-effectiveness compared with later. It was prospected that durability improvement of the former material by impurity control was more cost-effective for practical market development of the heat pump. Identification of impurities which inhibited repetitive durability and removal of them from precipitated material were useful methodologies for the development of cost effective and durable materials.

\subsection{Effect of dehydration on durability}

High temperature process of dehydration has also possibility to affect reduction of durability. The effect of dehydration duration time $\left(t_{\mathrm{d} \text {-dura }}\right)$ on repetitive durability was measured for $\mathrm{L}_{3} \mathrm{G}_{\text {treat }}$. Repetitive operations of 15 cycles each were measured under $t_{\text {d-dura }}=$ $15,25,35$ and $55 \mathrm{~min}$, respectively. Dehydration of a sample was observed until almost initial $10 \mathrm{~min}$, and the sample was left under the dehydration condition until the end of the duration time. Hydration reactivity changes of every cycle are shown in Figure 5. After initial 3 cycles, existence of optimum dehydration duration time was observed. Enhancement of reactivity between $t_{\mathrm{d} \text {-dura }}=15 \mathrm{~min}$ and 25 min means that reaction duration time extension has positive effect on dehydration in the period. Decrease of reactivity from $t_{\mathrm{d} \text {-dura }}=35 \mathrm{~min}$ to $55 \mathrm{~min}$ was caused by progress of agglomeration of primary particles.

As mentioned in the Section 2.2, the reactive nuclei production by the structure change from $\mathrm{Mg}(\mathrm{OH})_{2}$ to $\mathrm{MgO}$ is effective for hydration reactivity enhancement. In the dehydration process, it was presumed that the reactive nuclei were produced until initial $10 \mathrm{~min}$ by the dehydration, and the agglomeration accompanying the nuclei disappearance was proceeded mainly after $35 \mathrm{~min}$. The time period between $t_{\mathrm{d} \text {-dura }}=15$ and 25 min was assumed to be some transient time for structure change from dehydrated raw structure state to agglomeration state. It was assumed that the structure

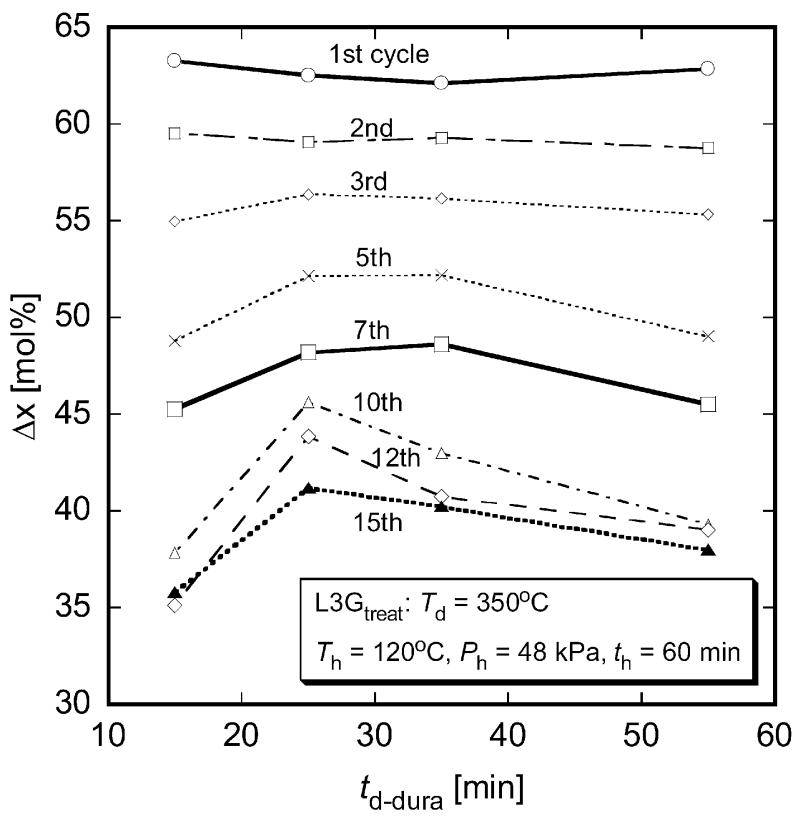

Fig. 5 Effect of dehydration time on repetitive durability for $L 3 G_{\text {treat }}$

change at the transient time was positive for the hydration reactivity enhancement, and then $\Delta x$ was enlarged between $t_{\mathrm{d} \text {-dura }}=15 \mathrm{~min}$ and $25 \mathrm{~min}$. It was inferred that structural water relocation in the material was one of reasons for the structure change in the period.

Figure 5 depicted the effect of dehydration duration time on repetitive heat pump operation and the existence of the optimal dehydration time. The specification of the structure change mechanism needed much more detailed analysis for temporal structure change in the dehydration.

\subsection{Thermal performance of the materials}

At hydration after 70 cycles in the condition of Figure 2, it was estimated from the experimental result that V05G-40 had a gross output of $725 \mathrm{~kJ} / \mathrm{kg}$ and $315 \mathrm{~kJ} / \mathrm{L}$ for $60 \mathrm{~min}$ operations. When the same amount of heat is stored by a conventional sensible heat water storage system using a temperature difference of $20^{\circ} \mathrm{C}$ between 70 and $90^{\circ} \mathrm{C}$, the heat output amount from water is around $83 \mathrm{~kJ} / \mathrm{kg}$. The heat storage density of the heat pump is estimated as 9 times that of the water storage system. The chemical heat pump would have a possibility to develop a new market on heat storage utilization and to contribute load leveling of cogeneration system.

\section{Conclusions}

Durable reaction materials for repetitive reaction operation of a chemical heat pump that used a reversible magnesium oxide/water reaction system were discussed to enhance the heat pump performance. Molded 
process for materials was expected to be suitable for multi-production method. A molded material made from ultra fine particle $\mathrm{MgO}$ which contains high-purity $\mathrm{MgO}$ over $99.8 \%$ of concentration had repetitive durability on 70 cycle repetitive operation. Impurity reduction from seawater precipitated $\mathrm{Mg}(\mathrm{OH})_{2}$ was effective on enhancement of repetitive durability operation. The cost of the precipitated hydroxide reduced impurities was less than one several tenths of the ultra fine particle material. A molded reactant made from the precipitated hydroxide was applicable for multi production and cost reduction of magnesium hydroxide material for the practical development of the heat pump. The thermal performance of magnesium oxide/ water chemical heat pump assumed to use the material based on the ultra fine particle was sufficiently competitive with a conventional sensible heat water storage system in terms of heat storage density and output temperature.

\section{Acknowledgements}

Authors greatly thank to Mr. Yuzo Kato, UBE Material Industries, Ltd. and the company itself for technical supports on the preparation of the materials.

\begin{tabular}{|c|c|c|}
\hline \multicolumn{2}{|c|}{ Nomenclature } & \\
\hline$M$ & $=$ & molecular mass $\quad[\mathrm{g} / \mathrm{mol}]$ \\
\hline$m_{\mathrm{Mg}(\mathrm{OH})_{2}}$ & $=$ & initial charged mass of $\mathrm{Mg}(\mathrm{OH})_{2}$ in the cell $[\mathrm{g}]$ \\
\hline$P$ & $=$ & pressure \\
\hline$T$ & $=$ & temperature \\
\hline$t$ & $=$ & reaction time \\
\hline$x$ & $=$ & mole reacted fraction change \\
\hline$x_{\text {ini }}$ & $=$ & $\begin{array}{l}\text { initial reacted fraction of hydration in a reaction } \\
\text { cycle }\end{array}$ \\
\hline$\Delta m$ & $=$ & mass change of measured sample \\
\hline$\Delta x$ & $=$ & reacted fraction change \\
\hline
\end{tabular}

$\begin{array}{rlr}\Delta x_{120} & = & \text { attained reacted fraction change in hydration after } \\ & 120 \mathrm{~min} & {[\mathrm{~mol} / \mathrm{mol}]} \\ \rho & = & \text { apparent material density }\end{array}$

$<$ Subscript $>$

$\begin{array}{ll}\mathrm{h} & =\text { hydration } \\ \mathrm{d} & =\text { dehydration } \\ \mathrm{d} \text {-dura } & =\text { duration of dehydration } \\ \mathrm{S} & =\text { saturated vapor }\end{array}$

\section{Literature Cited}

Bauerle, G. and D. K. Chung; "Storage of Thermal Energy in Inorganic/Hydroxide," Proc. of Int. Seminar on Thermochemical Energy Storage, pp. 205-246, Stockholm, Sweden (1980)

Bhatti, A. S. and D. Dollimore; "The Rates of Hydration of Sea Water Magnesias," Surf. Technol., 22, 181-188 (1984)

Ervin, G.; "Solar Heat Storage Using Chemical Reactions," J. Solid State Chem., 22, 51-61 (1977)

Itatani, K., K. Koizumi, F. S. Howell, A. Kishioka and M. Kinoshita; "Agglomeration of Magnesium Oxide Particles Formed by the Decomposition of Magnesium Hydroxide," J. Mater. Sci., 23, 3405-3412 (1988)

Kato, Y., N. Yamashita and Y. Yoshizawa; "Study of Chemical Heat Pump with Reaction System of Magnesium Oxide/Water," Kagaku Kogaku Ronbunshu, 19, 1213-1216 (1993)

Kato, Y., N. Yamashita, K. Kobayashi and Y. Yoshizawa; "Kinetic Study of the Hydration of Magnesium Oxide for a Chemical Heat Pump," Appl. Therm. Eng., 16, 853-862 (1996)

Kato, Y., K. Kobayashi and Y. Yoshizawa; "Durability to Repetitive Reaction of Magnesium Oxide/Water Reaction System for a Heat Pump," Appl. Therm. Eng., 18, 85-92 (1998)

Kato, Y., J. Nakahata and Y. Yoshizawa; "Durability Characteristics of the Hydration of Magnesium Oxide under Repetitive Reaction," J. Mater. Sci., 34, 475-480 (1999)

Kato, Y., A. Minakami, G. Li and Y. Yoshizawa; "Operability of a Thermally Driven Magnesium Oxide/Water Chemical Heat Pump," Can. J. Chem. Eng., 79, 536-541 (2001)

Kato, Y., K. Sasaki and Y. Yoshizawa; "Thermal Performance Measurement of a Packed Bed Reactor of a Magnesium Oxide/ Water Chemical Heat Pump," J. Chem. Eng. Japan, 36, 833839 (2003) 